\title{
Empirical series of journal h-indices: The JCR category Horticulture as a case study
}

\author{
YUXIAN LIU, ${ }^{\text {a }}$ I. K. RAVICHANDRA RAO, ${ }^{\text {b,c }}$ RONALD ROUSSEAU ${ }^{\mathrm{c}, \mathrm{d}}$ \\ ${ }^{a}$ Catalogue Section, Library of Tongji University, Siping Street 1239, 200092 Shanghai, P.R. China \\ ${ }^{\mathrm{b}}$ Indian Statistical Institute (ISI), $8^{\text {th }}$ Mile, Mysore Road, R.V. College, P.O. Bangalore, 560059, India \\ ${ }^{\mathrm{c}}$ Universiteit Hasselt, Campus Diepenbeek, Agoralaan, B-3590, Diepenbeek, Belgium \\ ${ }^{\mathrm{d}}$ KHBO (Association K.U.Leuven), Industrial Sciences and Technology, Zeedijk 101, \\ B-8400 Oostende, Belgium
}

Two types of series of h-indices for journals published in the field of Horticulture during the period 1998-2007 are calculated. Type I h-indices are based on yearly data, while type II h-indices use cumulative data. These h-indices are also considered in a form normalised with respect to the number of published articles.

It is observed that type I h-indices, normalised or not, decrease linearly over a period of ten years. The type II series, however, is not linear in nature: it exhibits partly a concave shape. This proves that the journals (in Horticulture) do not exhibit a linear increase in h-index as argued by Hirsch in the case of life-time achievements of scientists.

In the second part of the paper, an attempt is made to study the relative visibility of a journal and its change over time, based on h-indices of journals. It is shown that:

- the h-index over the complete period 1998-2007 of the journal Theoretical \& Applied Genetics $(\mathrm{h}=62)$ is much higher than that of all other journals in the field;

- the relation between the number of publications and the type II h-index for the whole period is not an exact power law (as it would have to be if the Egghe-Rousseau model were applicable);

- in order to study the dynamic aspects of journal visibility, a field-relative normalised h-ratio is defined to monitor systematic changes in the field of Horticulture. Except for two journals, the Pearson correlation coefficient for yearly values of this field-relative normalised h-ratio indicates that there is no systematic change of the performance of the journals with respect to the field as a whole.

\section{Introduction}

In 2005 Hirsch proposed the h-index to quantify an individual's scientific research output [HIRSCH, 2005]. He defined this index, also known as the Hirsch index, as follows. Consider a scientist's list of publications, ranked according to the number of citations received. Then this scientist's h-index is defined as the highest rank such that the first $\mathrm{h}$ publications received each at least $\mathrm{h}$ citations. Since its introduction many colleagues studied this new concept and extended its definition and application areas. BRAUN \& AL. [2006], for instance, applied it to compute an h-index for journals. It has

Received November 26, 2007; Published online March 18, 2009

Address for correspondence:

YUXIAN LIU

E-mail: yxliu@lib.tongji.edu.cn 
been argued that a journal h-index is robust and that it combines a quality and a quantity effect. BANKS [2006] applied the concept to the study of topics, see also [THE Stimulate-6 Group, 2007], while LiU \& RousseaU [2007] applied it to library data. During the $11^{\text {th }}$ International Conference of the ISSI RAO [2007] presented an article studying the distribution of the h- and g-indices of 168 scientists. From the discussions related to this presentation it became clear that more empirical data are needed to complement theoretical developments related to the h-index. In this paper we present such data related to series of journal h-indices.

\section{Time series of journal h-indices: definitions}

Series of h-indices or h-type indices have been studied before. As it is utterly impossible that one number such as the h-index fully characterises a scientist or a journal, a study of the change of this number over time comes one step closer to a complete description, and still has the advantage of being a summary statistic. The first to study series of h-indices was LIANG [2006]. She, however, considered a time series that goes backward in time. Her first h-index is the one for the year Y (publications and citations), the second one is related to publications in the years $\mathrm{Y}-1$ and $\mathrm{Y}$, and citations received during the same period. In general the $\mathrm{k}$-th element in a Liang sequence considers publications during the period $[\mathrm{Y}-\mathrm{k}+1, \mathrm{Y}]$ and citations received during the same period. ROUSSEAU [2006] considered a time series of h-indices for the journal JASIS and suggested that for the calculation of journal h-indices a normalisation with respect to the number of published articles would be appropriate.

BURRELL [2007C], based on a linear relation between the h-index and age (career age in the case of life-time achievements), proposed the h-rate as an alternative indicator. The existence of a linear relation between $\mathrm{h}$ and career age had been suggested by HIRSCH [2005] and confirmed by KELLY \& JENNIONS [2006]. We finally note that JIN \& AL. [2007] present a short time series of so-called AR-indices for the information scientist and Price awardee B. C. Brookes.

We keep a document set fixed and study series of h-indices for this document set. This document set can be a journal, as in most examples, but it can also be the set of all journals in one particular field, or even all journals in a database, such as the Web of Science. In this article the document set will either be articles published in one journal or articles published in a set of journals, namely journals in the field of Horticulture as defined by the corresponding JCR category.

Many different types of series of h-indices are possible [LIU \& ROUSSEAU, 2008] but we will only consider two types (types I and II, defined below), and focus on one in particular (type I). Consider a publication-citation matrix consisting of $\mathrm{N}$ publication years, from year $\mathrm{Y}$ to year $\mathrm{Y}+\mathrm{N}-1$ (the columns) and $\mathrm{M}$ citation years, from year $\mathrm{Y}$ to year $\mathrm{Y}+\mathrm{M}-1$ (the rows). Hence the publication-citation matrix is an $\mathrm{MxN}-$ matrix. It 
makes only sense to consider the case $\mathrm{M} \geq \mathrm{N}$. In this article the words series and sequence will be used as synonyms.

\section{Type I series}

The first h-index of a type I series is based on all articles published in the year $\mathrm{Y}$, and all citations received during the period [Y; $\mathrm{Y}+\mathrm{M}-1]$. The $\mathrm{k}^{\text {th }} \mathrm{h}$-index of this series is based on all articles published in the year $\mathrm{Y}+\mathrm{k}-1$, and all citations received during the period $[\mathrm{Y}+\mathrm{k}-1 ; \mathrm{Y}+\mathrm{M}-1]$. For the given publication-citation matrix this series consists of $\mathrm{N}$ elements. Type I series are illustrated in Figure 1: columns refer to publication years; rows to citation years. Note that we associate with each article the total number of citations received during the period indicated in grey. This series is denoted as

$$
\left(\mathrm{h}_{\mathrm{k}}^{\mathrm{I}}\right)_{\mathrm{k}=1, \ldots, \mathrm{N}}
$$

and contains $\mathrm{N}$ elements.

\begin{tabular}{|l|l|l|l|l|}
\hline Publication year / Citation year & $\mathrm{Y}$ & $\mathrm{Y}+1$ & $\mathrm{Y}+2$ & $\mathrm{Y}+3$ \\
\hline $\mathrm{Y}$ & & & & \\
\hline $\mathrm{Y}+1$ & & & & \\
\hline $\mathrm{Y}+2$ & & & & \\
\hline $\mathrm{Y}+3$ & & & & \\
\hline $\mathrm{Y}+4$ & $\mathrm{Y}$ & $\mathrm{Y}+1$ & $\mathrm{Y}+2$ & $\mathrm{Y}+3$ \\
\hline & & & & \\
\hline $\mathrm{Y}$ & & & & \\
\hline $\mathrm{Y}+1$ & & & & \\
\hline $\mathrm{Y}+2$ & & & & \\
\hline $\mathrm{Y}+3$ & & & & \\
\hline $\mathrm{Y}+4$ & $\mathrm{Y}$ & $\mathrm{Y}+1$ & $\mathrm{Y}+2$ & $\mathrm{Y}+3$ \\
\hline & & & & \\
\hline $\mathrm{Y}$ & & & & \\
\hline $\mathrm{Y}+1$ & & & & \\
\hline $\mathrm{Y}+2$ & & & & \\
\hline $\mathrm{Y}+3$ & & & & \\
\hline $\mathrm{Y}+4$ & $\mathrm{Y}$ & $\mathrm{Y}+1$ & $\mathrm{Y}+2$ & $\mathrm{Y}+3$ \\
\hline & & & & \\
\hline $\mathrm{Y}$ & & & & \\
\hline $\mathrm{Y}+1$ & & & & \\
\hline $\mathrm{Y}+2$ & & & & \\
\hline $\mathrm{Y}+3$ & & & & \\
\hline $\mathrm{Y}+4$ & & & & \\
\hline
\end{tabular}

Figure 1. An illustration of the calculation of a type I time series of h-indices (case $\mathrm{M}=5, \mathrm{~N}=4$ ) 


\section{Type II series}

The first element in a type II series is equal to the first element of the corresponding type I series. However, the $\mathrm{k}^{\text {th }} \mathrm{h}$-index of this series is based on all articles published in the period $[\mathrm{Y} ; \mathrm{Y}+\mathrm{k}-1]$, and all citations received during the period [Y; $\mathrm{Y}+\mathrm{M}-1]$. The type II series of $\mathrm{h}$-indices is denoted as $\left(\mathrm{h}_{\mathrm{k}}^{\mathrm{II}}\right)_{\mathrm{k}=1, \ldots, \mathrm{N}}$ and contains $\mathrm{N}$ elements. Type II series are illustrated in Figure 2 (grey areas are used for the determination of h-indices).

\begin{tabular}{|l|l|l|l|l|}
\hline Publication year / Citation year & $\mathrm{Y}$ & $\mathrm{Y}+1$ & $\mathrm{Y}+2$ & $\mathrm{Y}+3$ \\
\hline $\mathrm{Y}$ & & & & \\
\hline $\mathrm{Y}+1$ & & & & \\
\hline $\mathrm{Y}+2$ & & & & \\
\hline $\mathrm{Y}+3$ & & & & \\
\hline $\mathrm{Y}+4$ & $\mathrm{Y}$ & $\mathrm{Y}+1$ & $\mathrm{Y}+2$ & $\mathrm{Y}+3$ \\
\hline & & & & \\
\hline $\mathrm{Y}$ & & & & \\
\hline $\mathrm{Y}+1$ & & & & \\
\hline $\mathrm{Y}+2$ & & & & \\
\hline $\mathrm{Y}+3$ & & & & \\
\hline $\mathrm{Y}+4$ & $\mathrm{Y}$ & $\mathrm{Y}+1$ & $\mathrm{Y}+2$ & $\mathrm{Y}+3$ \\
\hline & & & & \\
\hline $\mathrm{Y}$ & & & & \\
\hline $\mathrm{Y}+1$ & & & & \\
\hline $\mathrm{Y}+2$ & & & & \\
\hline $\mathrm{Y}+3$ & & & & \\
\hline $\mathrm{Y}+4$ & $\mathrm{Y}$ & $\mathrm{Y}+1$ & $\mathrm{Y}+2$ & $\mathrm{Y}+3$ \\
\hline & & & & \\
\hline $\mathrm{Y}$ & & & & \\
\hline $\mathrm{Y}+1$ & & & & \\
\hline $\mathrm{Y}+2$ & & & & \\
\hline $\mathrm{Y}+3$ & & & & \\
\hline $\mathrm{Y}+4$ & & & & \\
\hline
\end{tabular}

Figure 2. An illustration of the calculation of a type II time series of h-indices (case $\mathrm{M}=5, \mathrm{~N}=4$ )

\section{Data collection and the calculation of $h$-indices of journals in the field of Horticulture}

We consider all journals in the category Horticulture of the Journal Citation Report (in short: JCR) (edition 2006). In this edition (2006) the Horticulture category contains 21 journals. Going back to the year 1998 we added all journals that were classified during the period 1998-2006 as horticultural journals by the staff of the JCR (at least once). Journals that changed names were grouped together (Fruit Varieties Journal 
became Journal of the American Pomological Society; Gartenbauwissenschaft became European Journal of Horticultural Science). In 1998 the field of Horticulture just consisted of 10 journals (what we might call traditional horticulture), later journals on wine research and on plant genetics were added. The journal Plant Varieties and Seeds completely stopped publication during this period.

In order to retrieve all articles published in one of these journals the following search string, restricted to the article document type was introduced in the Source Title field of a general search in the ISI Web of Knowledge (Thomson Scientific) on 15 September 2007.

BIOLOGICAL AGRICULTURE \& HORTICULTURE OR FRUIT VARIETIES JOURNAL OR GARTENBAUWISSENSCHAFT OR HORTSCIENCE OR JOURNAL OF THE AMERICAN SOCIETY FOR HORTICULTURAL SCIENCE OR JOURNAL OF HORTICULTURAL SCIENCE \& BIOTECHNOLOGY OR JOURNAL OF THE JAPANESE SOCIETY FOR HORTICULTURAL SCIENCE OR POSTHARVEST BIOLOGY AND TECHNOLOGY OR SCIENTIA HORTICULTURAE OR SEED SCIENCE AND TECHNOLOGY OR AMERICAN JOURNAL OF ENOLOGY AND VITICULTURE OR AUSTRALIAN JOURNAL OF GRAPE AND WINE RESEARCH OR EUPHYTICA OR EUROPEAN JOURNAL OF HORTICULTURAL SCIENCE OR EUROPEAN JOURNAL OF PLANT PATHOLOGY OR HORTTECHNOLOGY OR JOURNAL OF THE AMERICAN POMOLOGICAL SOCIETY OR JOURNAL INTERNATIONAL DES SCIENCES DE LA VIGNE ET DU VIN OR JOURNAL OF THE PROFESSIONAL ASSOCIATION FOR CACTUS DEVELOPMENT OR MOLECULAR BREEDING OR NEW ZEALAND JOURNAL OF CROP AND HORTICULTURAL SCIENCE OR THEORETICAL AND APPLIED GENETICS OR VITIS OR PLANT VARIETIES AND SEEDS

Publication year or range was set according to the specific case. Next, results were sorted by 'times cited', the number of retrieved articles were recorded and the h-index determined from the resulting list. This approach was faster than using the available 'Citation Report' option. Series of h-indices of type I and type II were collected. It turned out that the field is completely dominated by one journal: Theoretical and Applied Genetics, a journal which is only remotely related to classical horticulture.

\section{Results}

Table 1 shows the two series of h-indices for Horticulture. The last type II h-index (1998-now) is the equivalent of Hirsch's life-time achievement h-index (where the 'life' of the journal or the field is assumed to have started in 1998). We observe that this index reaches its final value very soon. The type I h-index decreases from publication year 1998 to publication year 2006 (actually 2007, but as this year is incomplete we do not take it into account). This decrease is expected, because the time span involved in the calculation decreases, but not a logical necessity. Indeed, it is theoretically possible that later issues receive more citations (even over a shorter time span). Examples of 
LIU \& AL.: Empirical series of journal h-indices: The JCR category Horticulture as a case study

such occurrences were found for individual journals, such as Seed Science and Technology (see Appendix).

Table 1. h-indices for the field of Horticulture (date: 15 September 2007)

\begin{tabular}{lclcrr}
\hline All journals & \multicolumn{5}{c}{} \\
\hline Publication Period & Type I h & \# publ & Publication Period & Type II h & \# publ \\
\hline 1998 & 48 & 2025 & 1998 & 48 & 2025 \\
1999 & 45 & 1850 & $1998-1999$ & 57 & 3875 \\
2000 & 40 & 1846 & $1998-2000$ & 62 & 5721 \\
2001 & 35 & 2059 & $1998-2001$ & 63 & 7780 \\
2002 & 33 & 2120 & $1998-2002$ & 65 & 9900 \\
2003 & 27 & 2029 & $1998-2003$ & 65 & 11929 \\
2004 & 22 & 2211 & $1998-2004$ & 65 & 14140 \\
2005 & 12 & 2248 & $1998-2005$ & 65 & 16388 \\
2006 & 7 & 2186 & $1998-2006$ & 65 & 18574 \\
2007 (partial) & 2 & 1165 & $1998-$ now & 65 & 19739 \\
\hline
\end{tabular}

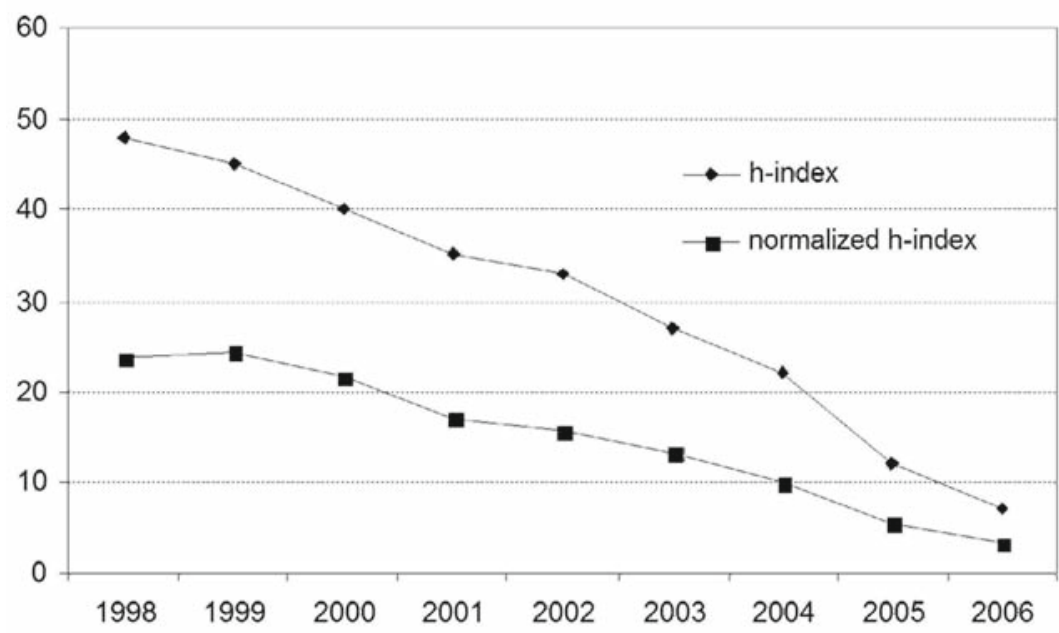

Figure 3. Time series of h-index (type I) of the field of Horticulture

Figure 3 shows the type I series before and after normalising with respect of the number of publications. Values shown for the normalised h-index are calculated as the h-index divided by the number of publications and multiplied by 1000 for clarity. The Pearson correlation coefficient of the two curves lies for both cases between -0.98 and -0.99 , indicating a decreasing linear trend. This decrease is expected as each h-index is calculated based on a more recent set of articles. The fact that it is linearly decreasing is expected but, as far as we know, a new factual finding for journal h-indices. 


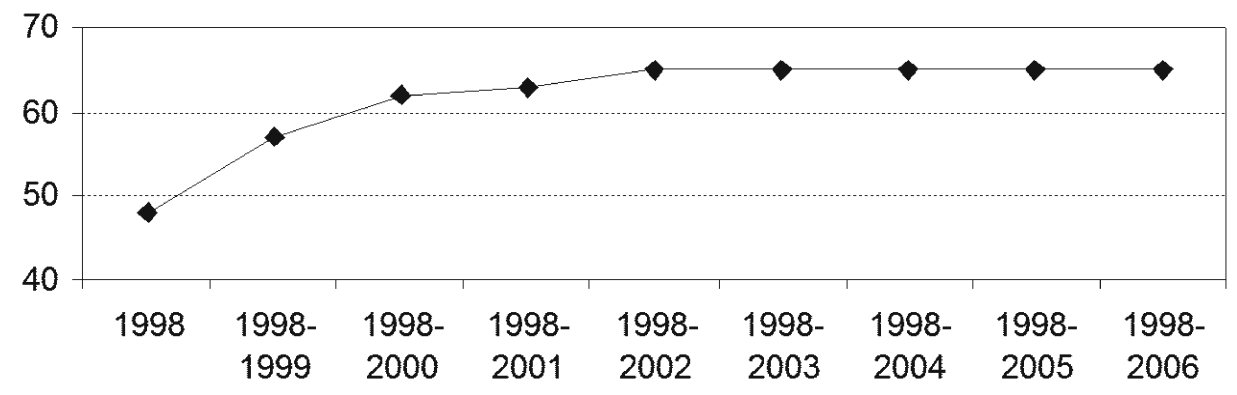

Figure 4. Time series of h-index (type II) of the field of Horticulture

The type II series (Figure 4) is not linear at all and has a concave shape - as predicted by EGGHE [2007] - before it becomes constant. This proves that journals do not exhibit the linear increase in h-index as suggested by Hirsch for scientists.

We further collected data for each journal separately and obtained their series of hindices. Results are shown in the appendix. Note that some journals were not covered by the JCR from 1998 on and others stopped publication (completely or temporarily).

\section{Considerations regarding journal visibility based on the $h$-index over the whole period 1998-2006}

In this section we investigate if information with respect to relative visibility (quality?) of a journal and its change over time can be obtained from these h-indices.

Does it make sense to compare h-indices or normalised h-indices? First, it is clear that the h-index of Theoretical and Applied Genetics $(\mathrm{h}=62)$ is much higher than that of all the other ones. No special analysis is needed to see that this journal is really the top journal in the field. Removing this journal from the analysis (otherwise it would have distorted the results), we obtained the best fitting power law to the remaining data (using nonlinear regression). It turns out that $\mathrm{h}=\mathrm{T}^{0.425}$ is the best fitting power law $\left(\mathrm{R}^{2}=0.353\right)$, where $\mathrm{T}$ denotes the total number of publications over the whole period. Note that, if a linear relation would have been the best fit we would have found this (or an exponent close to 1). This is, however, not the case.

EGGHE \& ROUSSEAU [2006] have argued that $\mathrm{h}=\mathrm{T}^{1 / \text { alpha }}$ under the assumption that the distribution of citations follows Lotka's power law with exponent alpha. In this case alpha turns out to be 2.35 (Figure 5). Clearly the model proposed by Egghe and Rousseau is not precise enough to explain the relation between the number of publications and the journal h-index in the field of Horticulture. 
However, as this power law is just a trend it can be used to separate journals performing above this trend and journals performing below it. In this sense Molecular Breeding $(\mathrm{h}=33)$ and Postharvest Biology and Technology $(\mathrm{h}=31)$ have a high $\mathrm{h}-$ index, both in an absolute as in a relative sense (this is: with respect to the number of publications). Yet, also Vitis $(\mathrm{h}=16)$ and the Australian Journal of Grape and Wine Research $(\mathrm{h}=12)$, although with a lower $\mathrm{h}$-index, perform very well relative to the number of publications. Hortscience $(\mathrm{h}=22)$ performs poor with respect to its number of publications (more than 2500) and also the Journal of the Japanese Society for Horticultural Science $(\mathrm{h}=12$ with 1088 publications) is a relatively poor performer.

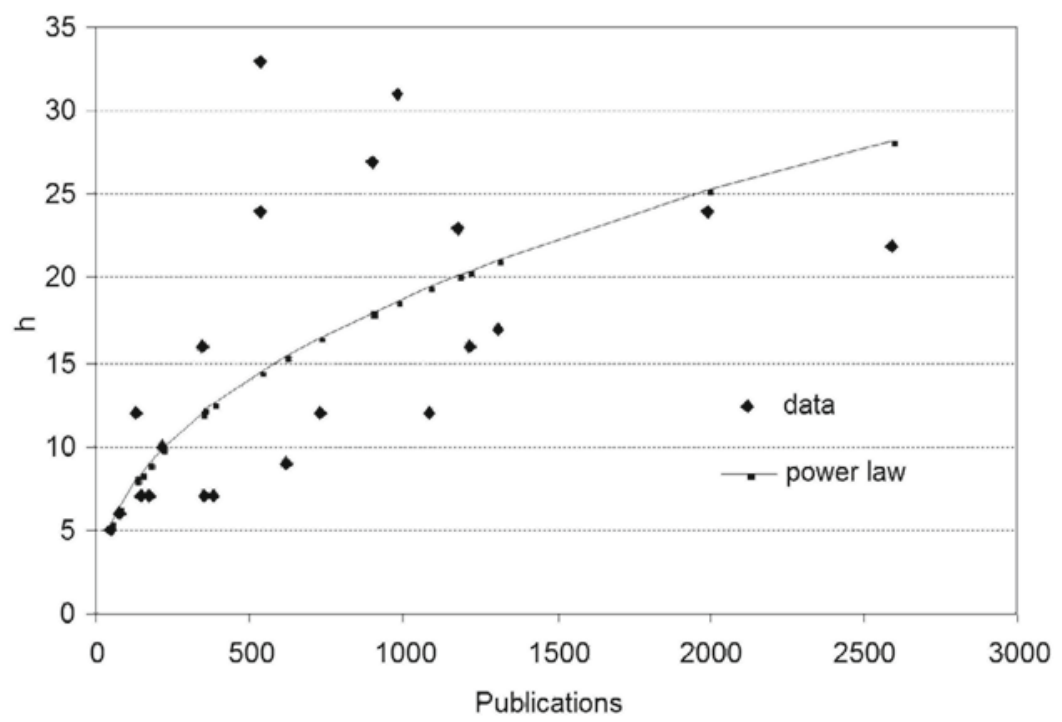

Figure 5. Best fitting power law (excl. Theoretical and Applied Genetics)

The overall shape (concavely increasing) of the type II index is very similar for all journals. Hence differences between journals are difficult to trace with a type II index. It seems that this series not suitable for studying dynamic aspects of journal visibility.

Finally, we considered for each journal $\mathrm{J}$ (for which we have complete data) the yearly values of the field-relative normalised h-ratio, defined as:

$$
\frac{h_{j}}{P b_{j}} / \frac{h_{F}}{P u b_{F}}=\frac{h_{j}}{h_{F}} / \frac{P_{j}}{P_{j} b_{F}}
$$

where the index F refers to the whole field. 
LIU \& AL.: Empirical series of journal h-indices: The JCR category Horticulture as a case study

Table 2. Pearson correlation coefficient for yearly values of the field-relative normalised h-ratio

\begin{tabular}{lc}
\hline Journal & $\mathrm{R}$ \\
\hline American Journal of Enology and Viticulture & 0.42 \\
Biological Agriculture \& Horticulture & 0.00 \\
Euphytica & 0.04 \\
European Journal of Plant Pathology & 0.47 \\
Gartenbauwissenschaft / European Journal of Horticultural Science & 0.95 \\
Horticultural Science & 0.11 \\
Hortscience & -0.23 \\
Journal of Horticultural Science \& Biotechnology & 0.00 \\
Journal of the American Society for Horticultural Science & 0.17 \\
Journal of the Japanese Society for Horticultural Science & 0.33 \\
Molecular Breeding & -0.72 \\
New Zealand Journal of Crop and Horticultural Science & 0.11 \\
Postharvest Biology and Technology & -0.38 \\
Scientia Horticulturae & 0.27 \\
Seed Science and Technology & 0.28 \\
Theoretical and Applied Genetics & 0.12 \\
Vitis & 0.44 \\
\hline
\end{tabular}

The critical values for a two-sided test $\left(\mathrm{H}_{0}: \mathrm{R}=0\right)$ on the $10 \%$ level are -0.669 and +0.669 [EGGHE \& RousseAU, 1990, p. 448]

It turns out that the Pearson correlation coefficient R for the period 1998-2004 is almost always very close to zero, indicating no systematic change of the performance of the journal with respect to the field (see Table 2). Two journals are an exception to this rule: Gartenbauwissenschaft / European Journal of Horticultural Science which shows an increasing trend, indicating that this journal is performing better over time, with respect to the field as a whole. This journal has experienced a name change, indicating a more international orientation. It seems that this strategy was successful.

The other exception is Molecular Breeding which is performing worse (decreasing trend for this indicator) than the field as a whole. Note that this observation is somewhat surprising as Molecular Breeding is among the best performers over the whole period. This proves that a time series analysis may reveal other characteristics than a one-point analysis, even if this one-point analysis is based on a long period (10 years).

\section{Conclusion}

Citation data were collected for each journal in Horticulture separately and for the field as a whole and series of h-indices were computed. Two types of series of h-indices for journals published in the field of Horticulture during the period 1998-2007, are analyzed. Type I h-indices are based on yearly data, while type II h-indices use cumulative data. These h-indices are also considered in a form normalised with respect to the number of published articles. 
It is observed that, as expected, type I h-indices as well as normalised h-indices are decreasing over a period of 10 years. The trend is linear in nature. However, the behaviour of type II series is not linear: it exhibits a concave increase until it stays constant. This shows that the journals (in Horticulture) do not exhibit a linear increase in the value of the h-index as argued by Hirsch, at least in the case of scientists' lifetime achievement.

In the second part of the paper, an attempt was made to study the relative visibility of a journal and its change over time, based on h-indices of journals. For this analysis we note the following three observations.

1. The h-index of the journal Theoretical \& Applied Genetics $(\mathrm{h}=62)$ is much higher than that of all other journals.

2. The Egghe-Rousseau power law model is not applicable to the field of Horticulture. Yet, the resulting model is used as a separator between high and low performers.

3. In order to study dynamic aspects of journal visibility, a field-relative normalised h-ratio is defined and studied in the field of Horticulture. Except for two journals, the Pearson correlation coefficient for yearly values of this field-relative normalised h-ratio indicates that there exists no systematic change of the performance of the journals with respect to the field as a whole.

As we found no evidence for the linear increase of the h-index over time (as proposed by Hirsch), nor for the Egghe-Rousseau model about the power law relation between the number of publications and the h-index, this suggests trying another approach, such as BURRELL's [2007A, B], something we consider out of the scope of this article, but which we hope to be able to do in the near future. Moreover, it is clear that collecting more empirical data on time series of h-type indices is necessary. Work on a characterisation of different h-type time series - a necessary first step - can be found in [LIU \& ROUSSEAU, 2008].

I.K.R. Rao thanks Hasselt University for financial support during the time he was a visiting professor and Prof. Egghe for his hospitality during his visit. Research of R. Rousseau was supported by the National Natural Science Foundation of China through grant no. 70673019. The authors thank Raf Guns (Antwerp University) for useful comments on an earlier draft.

\section{References}

BANKS, M. G. (2006), An extension of the Hirsch index: indexing scientific topics and compounds. Scientometrics, $69: 161-168$.

Braun, T., GlänZel, W., Schubert, A. (2006), A Hirsch-type index for journals. Scientometrics, $69: 169-173$.

BURRELL, Q. L. (2007A). Hirsch's h-index: a stochastic model. Journal of Informetrics, 1: 16-25. 
LIU \& AL.: Empirical series of journal h-indices: The JCR category Horticulture as a case study

Burrell, Q. L. (2007B). Hirsch's h-index and Egghe's g-index. In: D. TORRES-SAlinAs, H. F. MoED (Eds), Proceedings of ISSI 2007, Madrid, CSIC, pp. 162-169.

Burrell, Q. L. (2007C). Hirsch index or Hirsch rate? Some thoughts arising from Liang's data. Scientometrics, $73: 19-28$.

EGGHE, L. (2007), Dynamic h-index: the Hirsch index in function of time. Journal of the American Society for Information Science and Technology, $58: 452-454$.

EGGHe, L., Rousseau, R. (1990). Introduction to Informetrics. Amsterdam: Elsevier.

EGgHe, L., RousSEAU, R. (2006). An informetric model for the h-index. Scientometrics, 69 : 121-129.

Hirsch, J. E. (2005), An index to quantify an individual's scientific research output. Proceedings of the National Academy of Sciences of the United States of America, 102 : 16569-16572.

Jin, B. H., Liang, L. M., Rousseau, R., EgGHE, L. (2007), The R- and AR-indices: complementing the hindex. Chinese Science Bulletin, 52 : 855-863.

Kelly, C. D., Jennions M. D. (2006), The h index and career assessment by numbers. Trends in Ecology and Evolution, 21167-21170.

LiANG, L. M. (2006), H-index sequence and h-index matrix: constructions and applications. Scientometrics, $69: 153-159$.

LIU, Y. X., RousseAU, R. (2007), Hirsch-type indices and library management: the case of Tongji University Library. In: D. Torres-Salinas, H. F. MoEd (Eds) Proceedings of ISSI 2007, Madrid, CSIC, pp. 514-522.

LiU, Y. X., Rousseau, R. (2008), Definitions of time series in citation analysis with special attention to the h-index. Journal of Informetrics, 2 : 202-210.

RAO, I. K. R. (2007), Distributions of Hirsch-index and g-index: an empirical study, In: D. TORRES-SALINAS, H. F. MOED (Eds) Proceedings of ISSI 2007, Madrid, CSIC, pp. 655-658.

Rousseau, R. (2006), A case study: evolution of JASIS' h-index. Science Focus, 1 (1) : 16-17 (in Chinese). English version available at: E-LIS: ID-code 5430.

The Stimulate-6 Group (2007), The Hirsch index applied to topics of interest to developing countries. First Monday, 12 (2). http://www.firstmonday.org/issues/issue12_2/stimulate/ 
LIU \& AL.: Empirical series of journal h-indices: The JCR category Horticulture as a case study

\section{Appendix}

This appendix contains type I and type II h-indices for each journal and for each year during the period 1998-2006 (+ 2007 partially) if available. The Pearson correlation for the regression line of the type I h-index over the period 1998-2006 is also given (if data for its calculation are available).

\begin{tabular}{|c|c|c|c|c|c|}
\hline Biological Agriculture \& Horticulture & I & & $\mathrm{R}=-0.98$ & II & \\
\hline Publication Period & $\mathrm{h}$ & \# publ & Publication Period & $\mathrm{h}$ & \# publ \\
\hline 1998 & 7 & 19 & 1998 & 7 & 19 \\
\hline 1999 & 6 & 20 & $1998-1999$ & 8 & 39 \\
\hline 2000 & 6 & 25 & $1998-2000$ & 9 & 64 \\
\hline 2001 & 5 & 32 & $1998-2001$ & 10 & 96 \\
\hline 2002 & 4 & 22 & $1998-2002$ & 10 & 118 \\
\hline 2003 & 4 & 30 & $1998-2003$ & 10 & 148 \\
\hline 2004 & 2 & 19 & $1998-2004$ & 10 & 167 \\
\hline 2005 & 1 & 19 & 1998-2005 & 10 & 186 \\
\hline 2006 & 1 & 32 & 1998-2006 & 10 & 218 \\
\hline 2007 (partial) & 0 & 0 & 1998-now & 10 & 218 \\
\hline
\end{tabular}

\begin{tabular}{|c|c|c|c|c|c|}
\hline $\begin{array}{l}\text { Fruit Varieties Journal / Journal of the American Pomological } \\
\text { Society }\end{array}$ & I & & & II & \\
\hline Publication Period & $\mathrm{h}$ & \# publ & Publication Period & $\mathrm{h}$ & \# publ \\
\hline 1998 & 5 & 46 & 1998 & 5 & 46 \\
\hline 1999 & 5 & 37 & $1998-1999$ & 6 & 83 \\
\hline 2000 & 2 & 10 & $1998-2000$ & 6 & 93 \\
\hline 2001 & - & - & $1998-2001$ & 6 & 93 \\
\hline 2002 & - & - & $1998-2002$ & 6 & 93 \\
\hline 2003 & - & - & $1998-2003$ & 6 & 93 \\
\hline 2004 & 4 & 30 & 1998-2004 & 7 & 123 \\
\hline 2005 & 2 & 26 & $1998-2005$ & 7 & 149 \\
\hline 2006 & 1 & 26 & 1998-2006 & 7 & 175 \\
\hline 2007 (partial) & 2 & 21 & 1998-now & 7 & 196 \\
\hline
\end{tabular}

\begin{tabular}{|c|c|c|c|c|c|}
\hline $\begin{array}{l}\text { Gartenbauwissenschaft / European Journal of Horticultural } \\
\text { Science }\end{array}$ & I & & $\mathrm{R}=-0.77$ & II & \\
\hline Publication Period & $\mathrm{h}$ & \# publ & Publication Period & $\mathrm{h}$ & \# publ \\
\hline 1998 & 4 & 46 & 1998 & 4 & 46 \\
\hline 1999 & 5 & 46 & 1998-1999 & 5 & 92 \\
\hline 2000 & 5 & 43 & $1998-2000$ & 6 & 135 \\
\hline 2001 & 4 & 44 & $1998-2001$ & 6 & 179 \\
\hline 2002 & 4 & 37 & 1998-2002 & 6 & 216 \\
\hline 2003 & 5 & 42 & 1998-2003 & 7 & 258 \\
\hline 2004 & 3 & 37 & 1998-2004 & 7 & 295 \\
\hline 2005 & 2 & 44 & 1998-2005 & 7 & 339 \\
\hline 2006 & 0 & 44 & 1998-2006 & 7 & 383 \\
\hline 2007 (partial) & 0 & 15 & 1998-now & 7 & 398 \\
\hline
\end{tabular}

\begin{tabular}{|c|c|c|c|c|c|}
\hline Hortscience & $\mathrm{I}$ & & $\mathrm{R}=-0.98$ & II & \\
\hline Publication Period & $\mathrm{h}$ & \# publ & Publication Period & $\mathrm{h}$ & \# publ \\
\hline 1998 & 15 & 285 & 1998 & 15 & 285 \\
\hline 1999 & 15 & 247 & 1998-1999 & 19 & 532 \\
\hline 2000 & 14 & 287 & $1998-2000$ & 22 & 819 \\
\hline 2001 & 10 & 266 & 1998-2001 & 22 & 1085 \\
\hline 2002 & 8 & 252 & 1998-2002 & 22 & 1337 \\
\hline 2003 & 8 & 253 & $1998-2003$ & 22 & 1590 \\
\hline 2004 & 7 & 316 & $1998-2004$ & 22 & 1906 \\
\hline 2005 & 5 & 405 & 1998-2005 & 22 & 2311 \\
\hline 2006 & 3 & 275 & 1998-2006 & 22 & 2586 \\
\hline 2007 (partial) & 1 & 140 & 1998-now & 22 & 2726 \\
\hline
\end{tabular}


LIU \& AL.: Empirical series of journal h-indices: The JCR category Horticulture as a case study

\begin{tabular}{|c|c|c|c|c|c|}
\hline Journal of the American Society for Horticultural Science & I & & $\mathrm{R}=-0.998$ & II & \\
\hline Publication Period & $\mathrm{h}$ & \# publ & Publication Period & $\mathrm{h}$ & \# publ \\
\hline 1998 & 18 & 182 & 1998 & 18 & 182 \\
\hline 1999 & 16 & 115 & 1998-1999 & 20 & 297 \\
\hline 2000 & 15 & 116 & $1998-2000$ & 21 & 413 \\
\hline 2001 & 13 & 118 & $1998-2001$ & 23 & 531 \\
\hline 2002 & 11 & 150 & $1998-2002$ & 23 & 681 \\
\hline 2003 & 9 & 133 & $1998-2003$ & 23 & 814 \\
\hline 2004 & 7 & 126 & 1998-2004 & 23 & 940 \\
\hline 2005 & 5 & 130 & $1998-2005$ & 23 & 1070 \\
\hline 2006 & 3 & 104 & $1998-2006$ & 23 & 1174 \\
\hline 2007 (partial) & 1 & 72 & 1998-now & 23 & 1246 \\
\hline Journal of Horticultural Science \& Biotechnology & I & & $\mathrm{R}=-0.98$ & II & \\
\hline Publication Period & $\mathrm{h}$ & \# publ & Publication Period & $\mathrm{h}$ & \# publ \\
\hline 1998 & 12 & 124 & 1998 & 12 & 124 \\
\hline 1999 & 10 & 126 & 1998-1999 & 13 & 250 \\
\hline 2000 & 10 & 124 & $1998-2000$ & 15 & 374 \\
\hline 2001 & 9 & 127 & $1998-2001$ & 15 & 501 \\
\hline 2002 & 8 & 124 & $1998-2002$ & 16 & 625 \\
\hline 2003 & 7 & 147 & $1998-2003$ & 16 & 772 \\
\hline 2004 & 6 & 161 & $1998-2004$ & 16 & 933 \\
\hline 2005 & 4 & 128 & $1998-2005$ & 16 & 1061 \\
\hline 2006 & 2 & 158 & $1998-2006$ & 16 & 1219 \\
\hline 2007 (partial) & 1 & 71 & 1998-now & 16 & 1290 \\
\hline Journal of the Japanese Society for Horticultural Science & $\mathrm{I}$ & & $\mathrm{R}=-0.93$ & II & \\
\hline Publication Period & $\mathrm{h}$ & \# publ & Publication Period & $\mathrm{h}$ & \# publ \\
\hline 1998 & 8 & 188 & 1998 & 8 & 188 \\
\hline 1999 & 11 & 174 & 1998-1999 & 12 & 362 \\
\hline 2000 & 7 & 125 & $1998-2000$ & 12 & 487 \\
\hline 2001 & 7 & 125 & $1998-2001$ & 12 & 612 \\
\hline 2002 & 6 & 137 & $1998-2002$ & 12 & 749 \\
\hline 2003 & 4 & 92 & $1998-2003$ & 12 & 841 \\
\hline 2004 & 2 & 97 & 1998-2004 & 12 & 938 \\
\hline 2005 & 3 & 78 & $1998-2005$ & 12 & 1016 \\
\hline 2006 & 1 & 72 & $1998-2006$ & 12 & 1088 \\
\hline 2007 (partial) & 1 & 23 & 1998-now & 12 & 1111 \\
\hline Postharvest Biology and Technology & $\mathrm{I}$ & & $\mathrm{R}=-0.85$ & II & \\
\hline Publication Period & $\mathrm{h}$ & \# publ & Publication Period & $\mathrm{h}$ & \# publ \\
\hline 1998 & 15 & 62 & 1998 & 15 & 62 \\
\hline 1999 & 20 & 83 & $1998-1999$ & 24 & 145 \\
\hline 2000 & 21 & 104 & $1998-2000$ & 30 & 249 \\
\hline 2001 & 15 & 74 & $1998-2001$ & 30 & 323 \\
\hline 2002 & 16 & 105 & $1998-2002$ & 31 & 428 \\
\hline 2003 & 13 & 140 & $1998-2003$ & 31 & 568 \\
\hline 2004 & 12 & 126 & $1998-2004$ & 31 & 694 \\
\hline 2005 & 7 & 128 & $1998-2005$ & 31 & 822 \\
\hline 2006 & 4 & 159 & 1998-2006 & 31 & 981 \\
\hline 2007 (partial) & 1 & 118 & 1998-now & 31 & 1099 \\
\hline Scientia Horticulturae & $\mathrm{I}$ & & $\mathrm{R}=-0.90$ & II & \\
\hline Publication Period & $\mathrm{h}$ & \# publ & Publication Period & $\mathrm{h}$ & \# publ \\
\hline 1998 & 11 & 100 & 1998 & 11 & 100 \\
\hline 1999 & 10 & 116 & 1998-1999 & 13 & 216 \\
\hline 2000 & 9 & 114 & $1998-2000$ & 15 & 330 \\
\hline 2001 & 11 & 136 & $1998-2001$ & 17 & 466 \\
\hline 2002 & 10 & 168 & $1998-2002$ & 17 & 634 \\
\hline 2003 & 8 & 85 & $1998-2003$ & 17 & 719 \\
\hline 2004 & 6 & 163 & $1998-2004$ & 17 & 882 \\
\hline 2005 & 4 & 181 & $1998-2005$ & 17 & 1063 \\
\hline 2006 & 3 & 243 & 1998-2006 & 17 & 1306 \\
\hline 2007 (partial) & 1 & 151 & 1998-now & 17 & 1457 \\
\hline
\end{tabular}


LIU \& AL.: Empirical series of journal h-indices: The JCR category Horticulture as a case study

\begin{tabular}{|c|c|c|c|c|c|}
\hline Seed Science and Technology & I & & $\mathrm{R}=-0.86$ & II & \\
\hline Publication Period & $\mathrm{h}$ & \# publ & Publication Period & $\mathrm{h}$ & \# publ \\
\hline 1998 & 8 & 81 & 1998 & 8 & 81 \\
\hline 1999 & 6 & 100 & 1998-1999 & 10 & 181 \\
\hline 2000 & 6 & 86 & $1998-2000$ & 10 & 267 \\
\hline 2001 & 8 & 71 & $1998-2001$ & 11 & 338 \\
\hline 2002 & 6 & 66 & $1998-2002$ & 12 & 404 \\
\hline 2003 & 5 & 77 & $1998-2003$ & 12 & 481 \\
\hline 2004 & 3 & 87 & $1998-2004$ & 12 & 568 \\
\hline 2005 & 4 & 79 & $1998-2005$ & 12 & 647 \\
\hline 2006 & 2 & 81 & $1998-2006$ & 12 & 728 \\
\hline 2007 (partial) & 1 & 23 & 1998-now & 12 & 751 \\
\hline American Journal of Enology and Viticulture & I & & $\mathrm{R}=-0.97$ & II & \\
\hline Publication Period & $\mathrm{h}$ & \# publ & Publication Period & $\mathrm{h}$ & \# publ \\
\hline 1998 & 15 & 65 & 1998 & 15 & 65 \\
\hline 1999 & 18 & 74 & 1998-1999 & 21 & 139 \\
\hline 2000 & 13 & 57 & $1998-2000$ & 23 & 196 \\
\hline 2001 & 11 & 60 & $1998-2001$ & 23 & 256 \\
\hline 2002 & 9 & 54 & $1998-2002$ & 24 & 310 \\
\hline 2003 & 8 & 47 & $1998-2003$ & 24 & 357 \\
\hline 2004 & 6 & 62 & $1998-2004$ & 24 & 419 \\
\hline 2005 & 4 & 50 & $1998-2005$ & 24 & 469 \\
\hline 2006 & 3 & 66 & $1998-2006$ & 24 & 535 \\
\hline 2007 (partial) & 1 & 37 & 1998-now & 24 & 572 \\
\hline Australian Journal of Grape and Wine Research & I & & & II & \\
\hline Publication Period & $\mathrm{h}$ & \# publ & Publication Period & $\mathrm{h}$ & \# publ \\
\hline 1998 & - & - & & - & - \\
\hline 1999 & - & - & & - & - \\
\hline 2000 & - & - & & - & - \\
\hline 2001 & 8 & 18 & 2001 & 8 & 18 \\
\hline 2002 & 7 & 23 & 2001-2002 & 9 & 41 \\
\hline 2003 & 6 & 24 & 2001-2003 & 11 & 65 \\
\hline 2004 & 7 & 25 & 2001-2004 & 12 & 90 \\
\hline 2005 & 5 & 19 & 2001-2005 & 12 & 109 \\
\hline 2006 & 2 & 25 & 2001-2006 & 12 & 134 \\
\hline 2007 (partial) & 0 & 13 & 2001-now & 12 & 147 \\
\hline Euphytica & I & & $\mathrm{R}=-0.95$ & II & \\
\hline Publication Period & $\mathrm{h}$ & \# publ & Publication Period & $\mathrm{h}$ & \# publ \\
\hline 1998 & 19 & 238 & 1998 & 19 & 238 \\
\hline 1999 & 15 & 152 & $1998-1999$ & 20 & 390 \\
\hline 2000 & 16 & 175 & $1998-2000$ & 21 & 565 \\
\hline 2001 & 15 & 271 & $1998-2001$ & 23 & 836 \\
\hline 2002 & 14 & 286 & $1998-2002$ & 24 & 1122 \\
\hline 2003 & 12 & 249 & $1998-2003$ & 24 & 1371 \\
\hline 2004 & 8 & 196 & $1998-2004$ & 24 & 1567 \\
\hline 2005 & 5 & 207 & $1998-2005$ & 24 & 1774 \\
\hline 2006 & 2 & 216 & $1998-2006$ & 24 & 1990 \\
\hline 2007 (partial) & 1 & 137 & 1998-now & 24 & 2127 \\
\hline European Journal of Plant Pathology & $\mathrm{I}$ & & $\mathrm{R}=-0.91$ & II & \\
\hline Publication Period & $\mathrm{h}$ & \# publ & Publication Period & $\mathrm{h}$ & \# publ \\
\hline 1998 & 18 & 99 & 1998 & 18 & 99 \\
\hline 1999 & 17 & 91 & 1998-1999 & 22 & 190 \\
\hline 2000 & 12 & 94 & $1998-2000$ & 22 & 284 \\
\hline 2001 & 17 & 98 & $1998-2001$ & 26 & 382 \\
\hline 2002 & 14 & 101 & $1998-2002$ & 27 & 483 \\
\hline 2003 & 11 & 96 & $1998-2003$ & 27 & 579 \\
\hline 2004 & 9 & 103 & 1998-2004 & 27 & 682 \\
\hline 2005 & 6 & 109 & $1998-2005$ & 27 & 791 \\
\hline 2006 & 7 & 108 & 1998-2006 & 27 & 899 \\
\hline 2007 (partial) & 1 & 69 & 1998-now & 27 & 968 \\
\hline
\end{tabular}


LIU \& AL.: Empirical series of journal h-indices: The JCR category Horticulture as a case study

\begin{tabular}{|c|c|c|c|c|c|}
\hline Horttechnology & I & & & II & \\
\hline Publication Period & $\mathrm{h}$ & \# publ & Publication Period & $\mathrm{h}$ & \# publ \\
\hline 1998 & - & - & & - & - \\
\hline 1999 & - & - & & - & - \\
\hline 2000 & - & - & & - & - \\
\hline 2001 & 7 & 111 & 2001 & 7 & 111 \\
\hline 2002 & 7 & 100 & 2001-2002 & 9 & 211 \\
\hline 2003 & 5 & 97 & $2001-2003$ & 9 & 308 \\
\hline 2004 & 4 & 78 & 2001-2004 & 9 & 386 \\
\hline 2005 & 4 & 129 & 2001-2005 & 9 & 515 \\
\hline 2006 & 3 & 103 & 2001-2006 & 9 & 618 \\
\hline 2007 (partial) & 0 & 66 & 2001-now & 9 & 684 \\
\hline
\end{tabular}

\begin{tabular}{|c|c|c|c|c|c|}
\hline Journal International des Sciences de la Vigne et du Vin & I & & & II & \\
\hline Publication Period & $\mathrm{h}$ & \# publ & Publication Period & $\mathrm{h}$ & \# publ \\
\hline 1998 & - & - & & & \\
\hline \multicolumn{6}{|l|}{1999} \\
\hline \multicolumn{6}{|l|}{2000} \\
\hline 2001 & 5 & 19 & 2001 & 5 & 19 \\
\hline 2002 & 3 & 20 & 2001-2002 & 6 & 39 \\
\hline 2003 & 3 & 31 & 2001-2003 & 7 & 70 \\
\hline 2004 & 2 & 29 & $2001-2004$ & 7 & 99 \\
\hline 2005 & 2 & 21 & $2001-2005$ & 7 & 120 \\
\hline 2006 & 1 & 24 & 2001-2006 & 7 & 144 \\
\hline 2007 (partial) & 0 & 12 & 2001-now & 7 & 156 \\
\hline
\end{tabular}

\begin{tabular}{|c|c|c|c|c|c|}
\hline Journal of the Professional Association for Cactus Development & I & & & II & \\
\hline Publication Period & $\mathrm{h}$ & \# publ & Publication Period & $\mathrm{h}$ & \# publ \\
\hline 1998 & 3 & 10 & 1998 & 3 & 10 \\
\hline 1999 & 0 & 0 & 1998-1999 & 3 & 10 \\
\hline 2000 & 0 & 0 & $1998-2000$ & 3 & 10 \\
\hline 2001 & 2 & 11 & $1998-2001$ & 4 & 21 \\
\hline 2002 & 0 & 0 & 1998-2002 & 4 & 21 \\
\hline 2003 & 3 & 10 & $1998-2003$ & 4 & 31 \\
\hline 2004 & 3 & 8 & 1998-2004 & 5 & 39 \\
\hline 2005 & 1 & 7 & 1998-2005 & 5 & 46 \\
\hline 2006 & 1 & 6 & 1998-2006 & 5 & 52 \\
\hline 2007 (partial) & 0 & 0 & 1998-now & 5 & 52 \\
\hline
\end{tabular}

\begin{tabular}{|c|c|c|c|c|c|}
\hline Molecular Breeding & I & & $\mathrm{R}=-0.97$ & II & \\
\hline Publication Period & $\mathrm{h}$ & \# publ & Publication Period & $\mathrm{h}$ & \# publ \\
\hline 1998 & 20 & 55 & 1998 & 20 & 55 \\
\hline 1999 & 23 & 52 & 1998-1999 & 28 & 107 \\
\hline 2000 & 19 & 60 & 1998-2000 & 30 & 167 \\
\hline 2001 & 15 & 55 & 1998-2001 & 32 & 222 \\
\hline 2002 & 13 & 57 & 1998-2002 & 32 & 279 \\
\hline 2003 & 11 & 57 & 1998-2003 & 33 & 336 \\
\hline 2004 & 9 & 76 & 1998-2004 & 33 & 412 \\
\hline 2005 & 7 & 63 & 1998-2005 & 33 & 475 \\
\hline 2006 & 2 & 61 & 1998-2006 & 33 & 536 \\
\hline 2007 (partial) & 1 & 39 & 1998-now & 33 & 575 \\
\hline
\end{tabular}

\begin{tabular}{|c|c|c|c|c|c|}
\hline New Zealand Journal of Crop and Horticultural Science & I & & $\mathrm{R}=-0.96$ & II & \\
\hline Publication Period & $\mathrm{h}$ & \# publ & Publication Period & $\mathrm{h}$ & \# publ \\
\hline 1998 & 6 & 41 & 1998 & 6 & 41 \\
\hline 1999 & 5 & 39 & 1998-1999 & 7 & 80 \\
\hline 2000 & 5 & 31 & $1998-2000$ & 7 & 111 \\
\hline 2001 & 5 & 32 & 1998-2001 & 7 & 143 \\
\hline 2002 & 3 & 31 & 1998-2002 & 7 & 174 \\
\hline 2003 & 3 & 39 & 1998-2003 & 7 & 213 \\
\hline 2004 & 3 & 44 & 1998-2004 & 7 & 257 \\
\hline 2005 & 1 & 51 & 1998-2005 & 7 & 308 \\
\hline 2006 & 1 & 48 & 1998-2006 & 7 & 356 \\
\hline 2007 (partial) & 0 & 0 & 1998-now & 7 & 356 \\
\hline
\end{tabular}


LIU \& AL.: Empirical series of journal h-indices: The JCR category Horticulture as a case study

\begin{tabular}{|c|c|c|c|c|c|}
\hline Theoretical and Applied Genetics & I & & $\mathrm{R}=-0.99$ & II & \\
\hline Publication Period & $\mathrm{h}$ & \# publ & Publication Period & $\mathrm{h}$ & \# publ \\
\hline 1998 & 45 & 329 & 1998 & 45 & 329 \\
\hline 1999 & 41 & 322 & 1998-1999 & 52 & 651 \\
\hline 2000 & 36 & 340 & $1998-2000$ & 56 & 991 \\
\hline 2001 & 30 & 327 & $1998-2001$ & 58 & 1318 \\
\hline 2002 & 30 & 345 & $1998-2002$ & 60 & 1663 \\
\hline 2003 & 24 & 341 & $1998-2003$ & 60 & 2004 \\
\hline 2004 & 22 & 391 & $1998-2004$ & 62 & 2395 \\
\hline 2005 & 11 & 338 & $1998-2005$ & 62 & 2733 \\
\hline 2006 & 7 & 298 & $1998-2006$ & 62 & 3031 \\
\hline 2007 (partial) & 2 & 138 & 1998-now & 62 & 3169 \\
\hline Vitis & I & & $\mathrm{R}=-0.90$ & II & \\
\hline Publication Period & $\mathrm{h}$ & \# publ & Publication Period & $\mathrm{h}$ & \# publ \\
\hline 1998 & 9 & 39 & 1998 & 9 & 39 \\
\hline 1999 & 7 & 36 & 1998-1999 & 11 & 75 \\
\hline 2000 & 9 & 38 & $1998-2000$ & 13 & 113 \\
\hline 2001 & 9 & 42 & $1998-2001$ & 16 & 155 \\
\hline 2002 & 6 & 42 & $1998-2002$ & 16 & 197 \\
\hline 2003 & 6 & 39 & $1998-2003$ & 16 & 236 \\
\hline 2004 & 4 & 37 & $1998-2004$ & 16 & 273 \\
\hline 2005 & 2 & 36 & $1998-2005$ & 16 & 309 \\
\hline 2006 & 2 & 37 & $1998-2006$ & 16 & 346 \\
\hline 2007 (partial) & 1 & 20 & 1998-now & 16 & 366 \\
\hline Plant Varieties and Seeds & $\mathrm{I}$ & & & II & \\
\hline Publication Period & $\mathrm{h}$ & \# publ & Publication Period & $\mathrm{h}$ & \# publ \\
\hline 1998 & 4 & 16 & 1998 & 4 & 16 \\
\hline 1999 & 5 & 20 & 1998-1999 & 6 & 36 \\
\hline 2000 & 3 & 17 & $1998-2000$ & 6 & 53 \\
\hline 2001 & 3 & 22 & $1998-2001$ & 6 & 75 \\
\hline 2002 & - & - & $1998-2002$ & & \\
\hline 2003 & - & - & $1998-2003$ & & \\
\hline 2004 & - & - & $1998-2004$ & & \\
\hline 2005 & - & - & $1998-2005$ & & \\
\hline 2006 & - & - & $1998-2006$ & & \\
\hline 2007 (partial) & - & - & 1998-now & 6 & 75 \\
\hline
\end{tabular}

